\title{
Enraizamento adventício de estacas do maracujazeiro silvestre Passiflora mucronata Lam.: forma de veiculação e concentrações do ácido indol-3-butírico ${ }^{1}$
}

\author{
Rodrigo Sobreira Alexandre ${ }^{2}$, Poliana Rangel Costa ${ }^{3}$, Kristhiano Chagas $^{4}$, Lívia Giro Mayrinck ${ }^{5}$, \\ Jamile Lenhaus Detoni ${ }^{6}$, Edilson Romais Schmildt ${ }^{1}$ \\ http://dx.doi.org/10.1590/0034-737X201461040017
}

\section{RESUMO}

Passiflora mucronata Lam. apresenta como características ser ornamental, medicinal e resistente à bacteriose nas folhas, além de ser altamente resistente à antracnose nos frutos e ramos. Objetivou-se, com este trabalho, avaliar a forma de veiculação, líquida ou sólida, e as concentrações do ácido indol-3-butírico (AIB) no enraizamento adventício de estacas de $P$. mucronata. O experimento foi conduzido no delineamento de blocos ao acaso, em esquema fatorial $2 \times 5$ (formas de veiculação do AIB: líquida e sólida x concentrações de AIB: 0; 250; 500; 750 e 1000 mg L-1, se líquido, ou mg Kg${ }^{1}$, se sólido), com quatro repetições, de 16 estacas cada. As características avaliadas foram enraizamento (\%), número de raiz, comprimento da maior raiz $(\mathrm{cm})$, volume de raiz $\left(\mathrm{cm}^{3}\right)$ e massa de matéria seca de raiz $(\mathrm{g})$. Verificou-se que o enraizamento de estacas de P. mucronata Lam. independe da forma como é veiculado o AIB, se sólida ou líquida, porém a qualidade do sistema radicular, avaliada por meio do número, volume e massa de matéria seca de raízes, foi superior à obtida ao se empregar o AIB sólido. O comportamento do enraizamento, do número e do comprimento de raízes foi linear crescente, até a máxima concentração de AIB (1000 $\mathrm{mg} \mathrm{L}^{-1}$ ou $\left.\mathrm{mg} \mathrm{Kg}^{-1}\right)$.

Palavras-chave: propagação vegetativa, estaquia, AIB.

\section{ABSTRACT}

\section{Adventitious rooting of wild passionflower Passiflora mucronata Lam. cuttings: vehiculation ways and concentrations of indole-3-butyric acid}

Passiflora mucronata Lam. is an ornamental, medicinal plant and resistant to bacterial blight on leaves. In addition, it is highly resistant to anthracnose in fruits and branches. The objective of this study was to evaluate the vehicultaion way, liquid or solid, and concentrations of indole-3-butyric acid (IBA) on adventitious rooting of $P$. mucronatacuttings. The experiment was carried out in a randomized block design in a $2 \times 5$ factorial design (IBA vehiculation ways: liquid and solid x IBA concentrations: 0; 250; 500; 750 and $1000 \mathrm{mg} \mathrm{L}^{-1}$ for liquid or $\mathrm{mg} \mathrm{Kg}^{-1}$ for solid), with four replicates with 16 cuttings each. The characteristics evaluated were rooting $(\%)$, root number, longest root length $(\mathrm{cm})$, root volume $\left(\mathrm{cm}^{3}\right)$ and dry weight of root $(\mathrm{g})$. It was found that the rooting of $P$. mucronata Lam. does not depend on the way IBA is conveyed, solid or liquid, but the quality of the root system, evaluated by means of the number, volume and dry mass of roots was superior to the one achieved whensolid IBA was used. The behavior of rooting, number and length of roots increased linearly up to the maximum concentration of IBA (1000 mg L-1 $\left.\mathrm{or} \mathrm{mg} \mathrm{Kg}^{-1}\right)$.

Key words: cutting, IBA, vegetative propagation.

\footnotetext{
Recebido para publicação em 06/05/2013 e aprovado em 11/10/2013.

Fonte financiadora $\mathrm{CNPq}$

2 Engenheiro-Agrônomo, Doutor. Departamento de Ciências Agrárias e Biológicas, Universidade Federal do Espírito Santo, Centro Universitário Norte do Espírito Santo, Rodovia BR 101 Norte, Km 60, Bairro Litorâneo, 29932-540, São Mateus, Espírito Santo, Brasil. rodrigosobreiraalexandre@ gmail.com (autor para correspondência); e.romais.s@gmail.com ${ }^{3}$ Bióloga, Mestre. Departamento de Ciências Agrárias e Biológicas, Universidade Federal do Espírito Santo, Centro Universitário Norte do Espírito Santo, Rodovia BR 101 Norte, Km 60, Bairro Litorâneo, 29932-540, São Mateus, Espírito Santo, Brasil. poli.rangel@ hotmail.com

${ }^{4}$ Engenheiro-Agrônomo, Pós-Graduação em Agricultura Tropical. Departamento de Ciências Agrárias e Biológicas, Universidade Federal do Espírito Santo, Centro Universitário Norte do Espírito Santo, Rodovia BR 101 Norte, Km 60, Bairro Litorâneo, 29932-540, São Mateus, Espírito Santo, Brasil. kristhianoc@gmail.com

${ }^{5}$ Graduanda em Agronomia. Departamento de Ciências Agrárias e Biológicas, Universidade Federal do Espírito Santo, Centro Universitário Norte do Espírito Santo, Rodovia BR 101 Norte, Km 60, Bairro Litorâneo, 29932-540, São Mateus, Espírito Santo, Brasil. lgmayrinck@ hotmail.com

${ }^{6}$ Bióloga, Mestre. Instituto Federal do Espírito Santo, Rodovia Miguel Curry Carneiro, 799, Bairro Santa Luzia, 29830-000, Nova Venécia, Espírito Santo, Brasil. jldetoni@ifes.edu.br
} 


\section{INTRODUÇÃO}

A família Passifloraceae é representada por espécies de origem tropical e subtropical. Passiflora é o gênero mais rico, com aproximadamente 450 espécies, cerca de 200 delas nativas do Brasil (Souza et al., 2008). Em vegetações predominantemente arbustivas, de restinga, dos estados do Espírito Santo e Rio de Janeiro, foi detectada a presença da espécie P. mucronata Lam. (Magnago et al., 2011).

Morfologicamente, P. mucronata é considerada uma trepadeira herbácea, com caule delgado não lenhoso; volúvel, que se enrosca de maneira espiralada em torno de um suporte; com órgão preensor que apresenta sensibilidade localizada na estrutura responsável pela aderência ao suporte (Barros et al., 2009). A espécie apresenta grande potencial ornamental, por suas inúmeras características morfológicas, acima citadas, além das observadas por Meletti et al. (2011), como as flores brancas, fosforescentes, antese noturna, polinização feita por morcegos, floração intensa e quase contínua pelo ano todo.

Outras características também são atribuídas à espécie $P$. mucronata, como a sua utilidade medicinal sedativa e seu uso popular para insônia, calmante, vermes e hemorroidas (Boscolo \& Valle, 2008). Uma característica agronômica extremamente importante dessa espécie é a de ser resistente à bacteriose nas folhas, e, altamente resistente à antracnose nos frutos e ramos (Junqueira et al., 2005).

Há pouca informação científica sobre a propagação vegetativa da espécie em questão, sendo detectado apenas um trabalho com minienxertia de P. edulis Sims. sobre $P$. mucronata Lam. Este trabalho indica grande potencial de uso de $P$. mucronata como porta-enxerto para a espécie comercial, devido à facilidade de pegamento (80\%) (Alexandre et al., 2013). Entretanto, em relação à estaquia, nenhum trabalho científico foi encontrado com a espécie em estudo.

O objetivo deste trabalho foi avaliar a forma de veiculação, líquida ou sólida, e as concentrações do ácido indol-3-butírico (AIB), no enraizamento adventício de estacas de P. mucronata Lam.

\section{MATERIAL E MÉTODOS}

O trabalho foi desenvolvido em casa de vegetação na Fazenda Experimental do Centro Universitário Norte do Espírito Santo (CEUNES), pertencente à Universidade Federal do Espírito Santo (UFES), em janeiro de 2013.

Estacas, com uma folha e um nó, foram coletadas de plantas matrizes cultivadas em casa de vegetação do CEUNES/UFES. As folhas destas estacas tiveram os seus limbos reduzidos à metade de seu comprimento e suas bases foram cortadas em bisel simples.
Após esta preparação, as estacas foram submetidas aos tratamentos caracterizados por imersão de suas bases em concentrações de $0 ; 250 ; 500 ; 750$ e $1000 \mathrm{mg} \mathrm{L}^{-1}$, se por forma líquida, ou $\mathrm{m} \mathrm{Kg}^{-1}$, se por forma sólida. O AIB líquido foi previamente diluído em $\mathrm{NaOH}(2 \mathrm{M})$ e posteriormente, diluído em água destilada e, o AIB sólido, misturado em talco inerte como veiculador. Em seguida, as estacas foram plantadas em substrato Bioplant ${ }^{\circledR}$, disposto em bandejas de polietileno preto, com 32 células cada.

O experimento foi conduzido em delineamento de blo$\cos$ ao acaso, em esquema fatorial $2 \times 5$ (formas de veiculação do AIB: líquida e sólida x concentrações de AIB: $0 ; 250 ; 500 ; 750$ e $1000 \mathrm{mg} \mathrm{L}^{-1}$, se por forma líquida, ou $\mathrm{mg} \mathrm{Kg}^{-1}$, se por forma sólida), com quatro repetições, de 16 estacas cada.

As características avaliadas foram enraizamento (\%), número de raiz, comprimento da maior raiz $(\mathrm{cm})$, volume de raiz $\left(\mathrm{cm}^{3}\right)$ e massa de matéria seca de raiz $(\mathrm{g})$.

Os dados foram submetidos à análise de variância e as médias foram comparadas pelo teste de Tukey, a 5\% de probabilidade e, para os fatores quantitativos, utilizou-se a análise de regressão, por meio do Programa GENES (Cruz, 2013).

\section{RESULTADOS E DISCUSSÃO}

Neste trabalho, para as variáveis de qualidade do sistema radicular de $P$. mucronata Lam, como número de raízes, volume e massa de matéria seca, houve interação significativa $(P<0,01)$ entre o tipo de veiculador, líquido ou sólido, e as concentrações de AIB $(0,250,500,750$ e $1000 \mathrm{mg} \mathrm{L}^{-1}$, se líquido, ou $\mathrm{mg} \mathrm{Kg}^{-1}$, se sólido). Porém, para as variáveis enraizamento e comprimento da maior raiz, apesar de não serem afetadas pelo fator tipo de veiculador, as médias apresentaram diferença significativa $(P<0,01)$ para as concentrações de AIB.

$\mathrm{Na}$ espécie Eucalyptus cloeziana, o comportamento do enraizamento foi semelhante ao encontrado neste trabalho, ou seja, independe da forma como é veiculado o regulador, se sólida ou líquida (Almeida et al., 2007). Entretanto, em outras espécies, como em Psidium guajava L. cv. Século XXI (Yamamoto et al., 2010) e Ginkgo biloba L. (Bitencourt et al., 2010), a veiculação do AIB em talco é mais eficiente que em solução hidroalcoólica. Por outro lado, em mirtileiro cvs. Flórida e Clímax, a forma etanólica foi superior ao talco, para o enraizamento das estacas (Peña et al., 2012). Ferreira et al. (2009) não recomendam a utilização do talco, para o aumento da indução radicial, em estacas de Sapium glandulatum.

O enraizamento adventício das estacas de $P$. mucronata Lam. apresentou comportamento linear crescente até a concentração de $1000 \mathrm{mg} \mathrm{L}^{-1} \mathrm{ou} \mathrm{mg} \mathrm{Kg}^{-1}$ de AIB, se em formas líquida ou sólida, respectivamente. $\mathrm{Na}$ maior concentração da auxina, o enraizamento foi de $86,0 \%$ 
e, na sua ausência, de 65,47\%, diferença esta de $20 \%$ (Figura 1). Entretanto, verifica-se que a espécie apresenta a boa percentagem de enraizamento, mesmo na ausência da auxina.

Alguns fatores podem ajudar a explicar o enraizamento adventício de estacas da espécie $P$. mucronata Lam. sem o uso da auxina (Figura 1), como o acúmulo de zinco (Zn) nos tecidos. Este micronutriente é requerido na síntese do triptofano, o qual é o aminoácido precursor do ácido indol-3-acético (AIA), envolvido na formação de raízes adventícias (Mengel \& Kirkby, 1979; Blakesley et al., 1991). Lourenço Júnior \& Cuzzuol (2009), ao caracterizarem solos de duas formações de restinga e sua influência na constituição química foliar de Passiflora mucronata Lam. (Passifloraceae) e Canavalia rosea (Sw.) DC. (Fabaceae), observaram que os elementos químicos $\mathrm{P}, \mathrm{S}$, $\mathrm{Cu}$ e $\mathrm{Zn}$ acumularam-se em maiores concentrações em folhas de $P$. mucronata Lam., o que poderia ajudar na emissão de raízes.

O AIB é efetivo no enraizamento adventício nas fases de indução, iniciação e expressão, além de ser mais eficiente que outras auxinas, como AIA e ANA (Rout, 2006; Kesari et al., 2009). O comportamento linear crescente do enraizamento adventício em $P$. mucronata Lam. até a concentração de $1000 \mathrm{mg} \mathrm{L}^{-1}$ de AIB (Figura 1), mostra que o uso de maiores concentrações desta auxina pode promover acréscimos no percentual de enraizamento da espécie. Segundo Santos et al. (2012), o enraizamento adventício de estacas de $P$. cincinnata com $1000 \mathrm{mg} \mathrm{L}^{-1}$ de AIB apresentou média de $66,6 \%$.

Muitos fatores exógenos e endógenos regulam a formação de raízes adventícias, como $\mathrm{Ca}^{2+}$, açúcares, auxinas, poliaminas, co-polímero de etileno, óxido nítrico, peróxido de hidrogênio, monóxido de carbono, cGMP, MAPKs e peroxidases. Esses mediadores parecem funcionar como sinalizadores e a auxina exerce um papel na transdução dos sinais, durante a formação de raízes adventícias (Li et al., 2009).

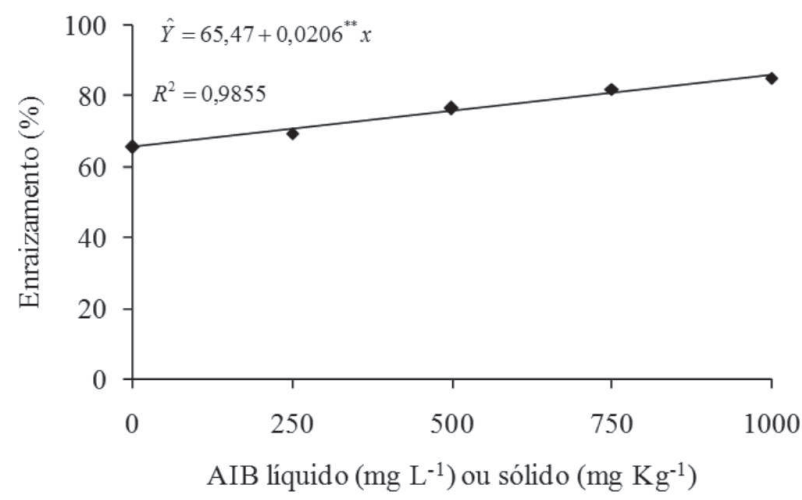

Figura 1. Enraizamento adventício de estacas de $P$. mucronata Lam. submetidas a diferentes concentrações de AIB.
Por outro lado, a espécie Passiflora nitida atingiu valores mais elevados de enraizamento $(83,75 \%)$, porém com uma concentração estimada de $3750 \mathrm{mg} \mathrm{L}^{-1}$ de AIB (Sabião et al., 2011), $2750 \mathrm{mg} \mathrm{L}^{-1}$ a mais do que foi usado em estacas de $P$. mucronata Lam. deste trabalho. A espécie $P$. alata (material silvestre) apresentou dificuldades no enraizamento adventício, mesmo em estacas tratadas com AIB (0, 500, 1000 e $\left.2000 \mathrm{mg} \mathrm{L}^{-1}\right)$, sendo obtidos os maiores resultados $(41,3 \%)$ com a concentração de 500 $\mathrm{mg} \mathrm{L}^{-1}$ (Roncatto et al., 2008). Salomão et al. (2002), entretanto, obtiveram com a mesma espécie $P$. alata média de $74,33 \%$ de enraizamento sem o uso de regulador. Por outro lado, em $P$. giberti a não utilização da auxina foi a melhor opção, apesar do baixo enraizamento $(37,21 \%)$. Nas espécies $P$. edulis, $P$. nitida e $P$. setacea, o efeito da ausência da auxina não diferiu daquele das demais concentrações estudadas, com médias de 22,75; 22,83 e 4,72\%, respectivamente (Roncatto et al., 2008).

Entretanto, espécies comerciais, como o maracujazeiro amarelo $P$. edulis Sims., mesmo quando não submetidas a tratamentos com reguladores de crescimento, atingiram média de enraizamento de $87 \%$ em todos os tipos de estacas estudadas (apical, mediana e basal) (Salomão et al., 2002).

Para a variável comprimento da maior raiz, não houve diferença entre as formas de aplicação do AIB (líquida ou sólida). Entretanto, o efeito foi significativo para as concentrações utilizadas, apresentando, portanto, comportamento linear crescente até a máxima concentração utilizada de AIB (1000 mg L ou mg Kg$^{-1}$ ) (Figura 2), indicando que, possivelmente, maiores concentrações desta auxina possam estimular o crescimento das raízes. O mesmo comportamento é observado em $P$. nitida, no qual o comprimento de raízes teve aumento linear até a máxima concentração de AIB (5000 $\mathrm{mg} \mathrm{L}^{-1}$ ) (Sabião et al., 2011).

Em ambas as formas de veiculação, o comportamento quanto ao número de raízes foi linear crescente, mas superior quando se utilizou a forma sólida, ou seja, por meio

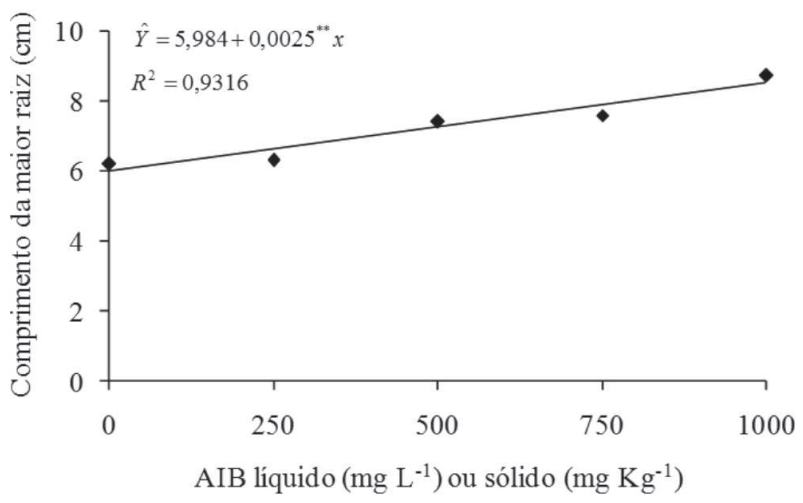

Figura 2. Comprimento da maior raiz $(\mathrm{cm})$ de estacas de $P$. mucronata Lam. tratadas com diferentes concentrações de AIB. 
de talco inerte. O AIB sólido (1000 $\left.\mathrm{mg} \mathrm{Kg}^{-1}\right)$ produziu 13,26 raízes, enquanto, na forma líquida $\left(1000 \mathrm{mg} \mathrm{L}^{-1}\right)$, apenas 4,71 (Figura 3), diferença de oito raízes, ou seja, resultado aproximadamente três vezes maior ao se utilizar a forma sólida da auxina (Figura 3). O efeito positivo do AIB sólido, em relação ao do AIB líquido, pode ser atribuído à sua aderência uniforme na base da estaca por um tempo suficiente, o que depende da umidade da base, e pelo pouco tempo de imersão, apenas cinco segundos, na forma lí-

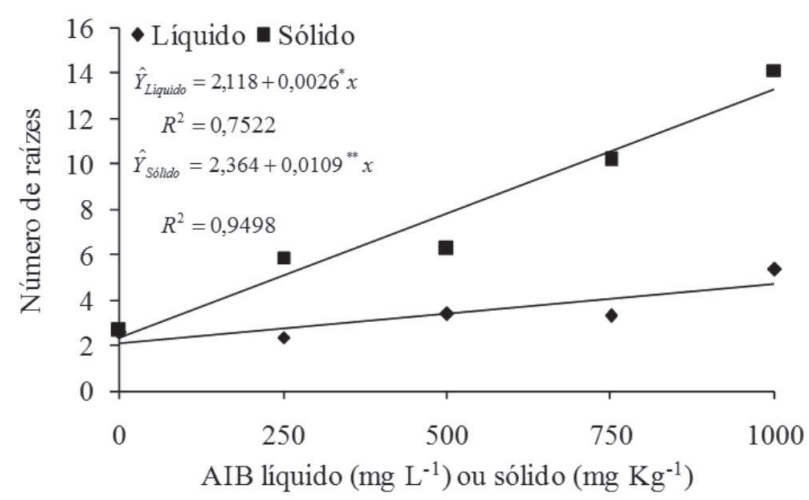

Figura 3. Número de raízes de estacas de $P$. mucronata Lam. submetidas a diferentes concentrações de AIB.

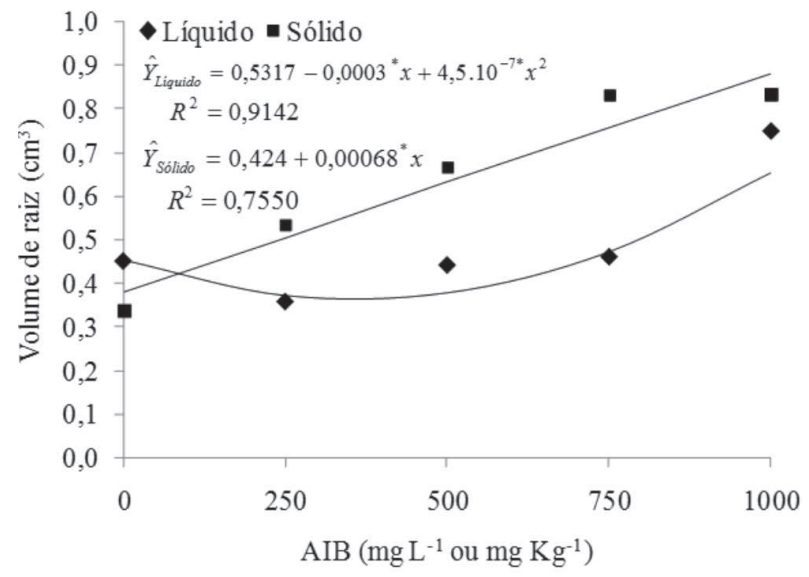

Figura 4. Volume de raízes de estacas de P. mucronata Lam. tratadas com diferentes concentrações de AIB.

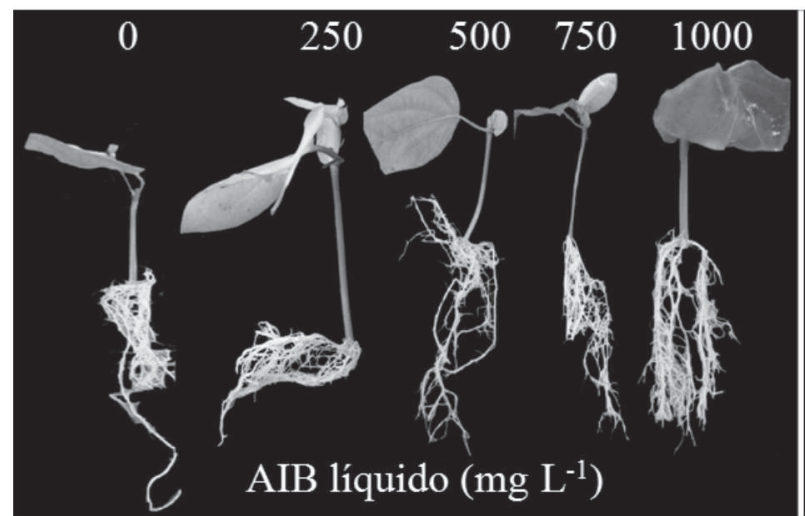

quida, o que pode não ter sido suficiente para induzir eficazmente ao enraizamento.

O mesmo comportamento linear também foi observado nas espécies silvestres Passiflora setacea, $P$. coccinea, $P$. amethystina, $P$. edulis, $P$. edulis $\times$ $P$. setacea e $P$. coccinea $\mathrm{x} P$. setacea, para o número de estacas com raiz e com broto, até a concentração de $1000 \mathrm{mg} \mathrm{L}^{-1}$ de AIB (Vaz et al., 2009).

Com a aplicação de AIB na forma sólida, o volume e a massa de matéria seca de raiz apresentam comportamento linear crescente até a concentração de 1000 mg $\mathrm{Kg}^{-1}$ de AIB (Figura 4 e 5, respectivamente). Para esta concentração, o volume de raiz foi de $1,104 \mathrm{~cm}^{3}$ e a massa de matéria seca de raiz de 0,8817 g. Em comparação, com o tratamento em solução líquida, na concentração de $1000 \mathrm{mg} \mathrm{L}^{-1}$ de AIB, obteve-se volume de $0,6817 \mathrm{~cm}^{3} \mathrm{e}$ massa de matéria seca de raiz de 0,6532 g (Figura 4 e 5, respectivamente).

Diferentemente do que foi observado para a espécie P. mucronata Lam., as espécies Passiflora setacea, $P$. coccinea, $P$. amethystina, $P$. edulis, $P$. edulis $\times$ P. setacea e $P$. coccinea $\mathrm{x} P$. setacea apresentaram comportamento linear crescente para a massa de matéria seca de raiz até a concentração de $1000 \mathrm{mg} \mathrm{L}^{-1}$ de AIB (Vaz et al., 2009).

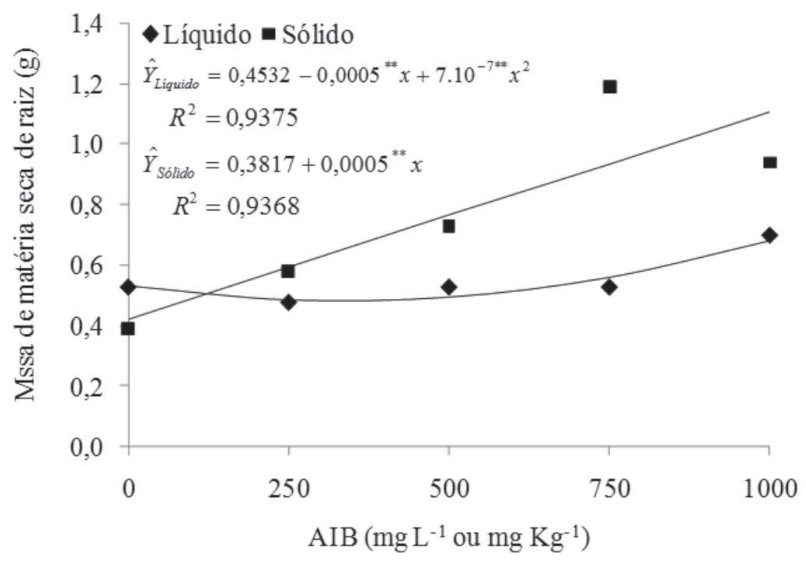

Figura 5. Massa de matéria seca de raiz (g) de estacas de $P$. mucronata Lam. tratadas com diferentes concentrações de AIB.

Figura 6. Estacas enraizadas de P. mucronata Lam. tratadas com diferentes concentrações de AIB.

Rev. Ceres, Viçosa, v. 61, n.4, p. 567-571, jul/ago, 2014 
Observa-se, na Figura 6, que a veiculação sólida do AIB proporciona maior volume de raízes, em comparação com o obtido com a forma líquida. Esses resultados são importantes porque esta forma de veiculação auxínica é mais prática para viveiristas, apesar de muitos já utilizarem, em outras espécies, como em pimenteira-do-reino (Piper nigrum L.), a forma sólida, por via do talco, conforme verificado também no trabalho de Serrano et al. (2012).

\section{CONCLUSÕES}

O enraizamento de estacas de P. mucronata Lam. independe da forma como é veiculado o AIB, se sólida ou líquida.

O comportamento de enraizamento, número e comprimento de raízes de $P$. mucronnata Lam. foi linear crescente até a máxima concentração de AIB (1000 mg L-1 ou mg Kg ${ }^{-1}$ ).

A qualidade do sistema radicular, avaliada por meio do número, volume e massa de matéria seca de raízes de $P$. mucronata Lam. foi superior à obtida com a forma líquida, ao se utilizar o AIB sólido.

É necessário estudar valores superiores a $1000 \mathrm{mg} \mathrm{Kg}^{-1}$ de AIB para identificar uma concentração ideal para o enraizamento adventício de $P$. mucronata Lam.

\section{REFERÊNCIAS}

Alexandre RS, Lopes JC, Tiradentes AT, Bruckner CH \& Otoni WC (2013) Metodologia de minienxertia em maracujazeiros. Revista Brasileira de Fruticultura, 35:329-332.

Almeida FD de, Xavier A, Dias JMM \& Paiva HN (2007) Eficiência das auxinas (AIB e ANA) no enraizamento de miniestacas de clones de Eucalyptus cloeziana F. Muell. Revista Árvore, 31:455463

Barros AAM de, Ribas L de A \& Araujo DSD (2009) Trepadeiras do Parque Estadual da Serra da Tiririca, Rio de Janeiro, Brasil. Rodriguésia, 60:681-694.

Bitencourt J, Zuffellato-Ribas KC \& Koehler HS (2010) Estaquia de Ginkgo biloba L. utilizando três substratos. Revista Brasileira de Plantas Medicinais, 12:135-140

Blakesley D, Weston GD \& Hall JF (1991) The role of endogenous auxin in root initiation. Plant Growth Regulation, 10:341-353.

Boscolo OH \& Valle L de S (2008) Planta de uso medicinal em Quissamã, Rio de Janeiro, Brasil. Iheringia. Série Botânica, 63:263-277.

Cruz CD (2013) Genes: a software package for analysis in experimental statistics and quantitative genetics. Acta Scientiarum. Agronomy, 35:271-276.

Ferreira BGA, Zuffellato-Ribas KC, Carpanezzi AA, Tavares FR \& Koehler HS (2009) Metodologias de aplicação de AIB no enraizamento de estacas semilenhosas de Sapium glandulatum (Vell.) Pax. Revista Brasileira de Plantas Medicinais, 11:196201

Junqueira NTV, Braga MF, Faleiro FG, Peixoto JR \& Bernacci LC (2005) Potencial de espécies silvestres de maracujazeiro como fonte de resistência a doenças. In: Faleiro FG, Junqueira NTV \& Braga MF (Eds.) Maracujá: germoplasma e melhoramento genético. Planaltina, Embrapa Cerrados. p.1-106.
Kesari V, Krishnamachari A \& Rangan L (2009) Effect of auxins on adventitious rooting from stem cuttings of candidate plus tree Pongamia pinnata (L.), a potential biodiesel plant. Trees, 23:597-604.

Li S-W, Xue L, Xu S, Feng H \& An L (2009) Mediators, genes and signaling in adventitious rooting. The Botanical Review, 75:230247.

Lourenço Júnior J \& Cuzzuol GRF (2009) Caracterização de solos de duas formações de restinga e sua influência na constituição química foliar de Passiflora mucronata Lam. (Passifloraceae) e Canavalia rosea (Sw.) DC. (Fabaceae). Acta Botânica Brasílica, 23:239-246

Magnago LFS, Martins SV \& Pereira OJ (2011) Heterogeneidade florística das fitocenoses de restingas nos estados do Rio de Janeiro e Espírito Santo. Revista Árvore, 35:245-254.

Meletti LMM, Soares-Scott MD, Bernacci LC, Alvares V \& Azevedo Filho JA de (2011) Caracterização de Passiflora mucronata Lam.: nova alternativa de maracujá ornamental. Revista Brasileira de Horticultura Ornamental, 17:87-95.

Mengel K \& Kirkby EA (1979) Principles of plant nutrition. Worblaufer-Bern, International Potash Institute. 579p.

Peña MLP, Gubert C, Tagliani MC, Bueno PMC \& Biasi LA (2012) Concentrações e formas de aplicação do ácido indolbutírico na propagação por estaquia dos mirtileiros cvs. Flórida e Clímax. Semina: Ciências Agrárias, 33:57-64.

Roncatto G, Nogueira Filho GC, Ruggiero C, Oliveira JC \& Martins ABG (2008) Enraizamento de estacas herbáceas de diferentes espécies de maracujazeiro. Revista Brasileira de Fruticultura, 30:1094-1099.

Rout GR (2006) Effect of auxins on adventitious root development from single node cuttings of Camellia sinensis (L.) Kuntze and associated biochemical changes. Plant Growth Regulation, 48:111-117.

Sabião RR, Silva A de CC da, Martins ABG \& Cardoso ER (2011) Enraizamento de estacas de Passiflora nítida submetidas a diferentes concentrações de ácido indolbutírico (AIB). Revista Brasileira de Fruticultura, 33:654-657.

Salomão LCC, Pereira WE, Duarte RCC \& Siqueira DL de (2002) Propagação por estaquia dos maracujazeiros doce (Passiflora alata Dryand.) e amarelo (P. edulis f. flavicarpa $\mathrm{O}$. Deg.). Revista Brasileira de Fruticultura, 24:163-167.

Santos JL, Matsumoto SN, D' Arêde LO, Luz IS da \& Viana AES (2012) Propagação vegetativa de estacas de Passiflora cincinnata Mast. em diferentes recipientes e substratos comerciais. Revista Brasileira de Fruticultura, 34:581-588.

Serrano LAL, Marinato FA, Magiero M, Sturm GM (2012) Produção de mudas de pimenteira-do-reino em substrato comercial fertilizado com adubo de liberação lenta. Revista Ceres, 59:512517.

Souza MM, Pereira TNS \& Vieira MLC (2008) Cytogenetic studies in some species of Passiflora L. (Passifloraceae): a review emphasizing Brazilian species. Brazilian Archives of Biology of Technology, 51:247-258.

Vaz C de F, Peixoto JR, Junqueira NTV, Braga MF, Santos EC dos, Fonseca KG da \& Junqueira KP (2009) Enraizamento de espécies silvestres de maracujazeiro utilizando cinco doses de ácido indolilbutírico. Revista Brasileira de Fruticultura, 31:816-822.

Yamamoto LY, Borges R de S, Sorace M, Rachid BF, Ruas JMF, Sato O, Assis AM \& Roberto SR (2010) Enraizamento de estacas de Psidium guajava L. 'Século XXI' tratadas com ácido indolbutírico veiculadas em talco e álcool. Ciência Rural, 40:1037-1042.

Rev. Ceres, Viçosa, v. 61, n.4, p. 567-571, jul/ago, 2014 